Review

\title{
Modulation of tight junction integrity by food components
}

\author{
Agnieszka Kosińska a,b,*, Wilfried Andlauer ${ }^{\text {a }}$ \\ a University of Applied Sciences Valais, Institute of Life Technologies, Route du Rawyl 47, CH-1950 Sion, Switzerland \\ ${ }^{\mathrm{b}}$ Division of Food Science, Institute of Animal Reproduction and Food Research, Polish Academy of Sciences, Tuwima 10, 10-747 Olsztyn, Poland
}

\section{A R T I C L E I N F O}

\section{Article history:}

Received 27 July 2012

Accepted 7 December 2012

\section{Keywords:}

Tight junction

Epithelial barrier modulation

Phenolic compounds

Paracellular transport

Food components

\begin{abstract}
A B S T R A C T
The primary function of the human intestine is to absorb nutrients and water. However, equally important is its ability to act as a selective barrier to protect the human system. Intestinal epithelium is formed by a monolayer of epithelial cells. Adjacent cells of the monolayer are sealed together by the formation of tight junctions (TJs)complex protein systems. The structure of $\mathrm{TJ}$ involves transmembrane proteins linked to a cytoplasmic plaque, which is formed by a network of scaffolding and adaptor proteins, signalling components and actin-binding cytoskeleton linkers. TJs regulate paracellular transport of compounds as well as physical barrier function of epithelium, which is linked to pathogenesis of inflammatory bowel disease, ulcerative colitis, Crohn's disease and food allergies. Epithelium is intensively exposed to food components. Various food components can affect the functioning of TJ by modifying expression of TJ protein components and affecting signalling pathways involved in $\mathrm{TJ}$ regulation. The targeted usage of food components to modulate TJ permeability is of vital importance for enhancing the absorption of poorly permeable drugs or bioactive compounds and, on the other hand, for sealing the junction in order to limit the risk of intestine pathology.

The aim of this review is to compile and analyse the previous research investigating the possible relevance of food components to TJ regulation, with a special consideration of phenolic compounds.
\end{abstract}

(c) 2013 Elsevier Ltd. All rights reserved.

\section{Contents}

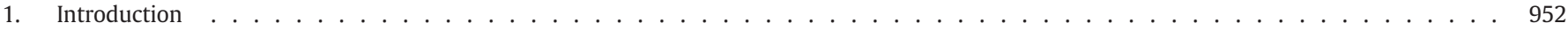

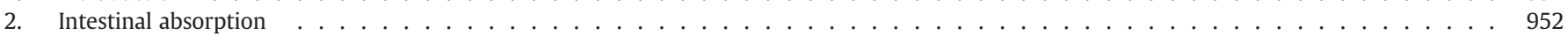

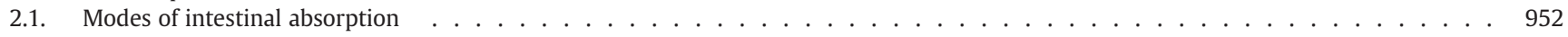

2.2. Permeability of $\mathrm{TJ} \ldots \ldots \ldots \ldots$

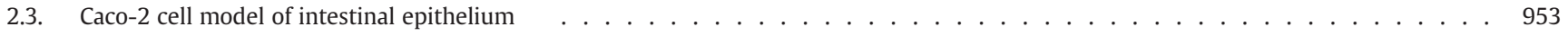

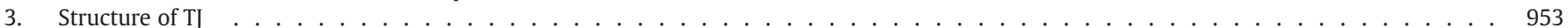

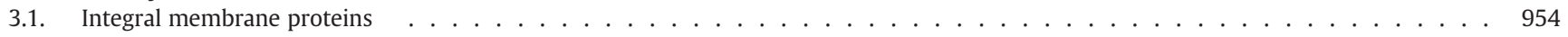

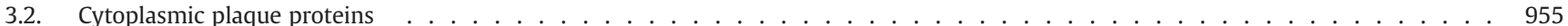

3.3. Cytoskeletal proteins $\ldots \ldots \ldots \ldots$

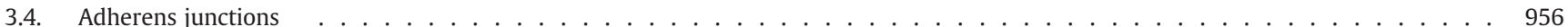

4. Modulation of $\mathrm{TJ} \ldots \ldots \ldots \ldots \ldots$

4.1. Food components as absorption enhancers f . . . . . . . . . . . . . . . . . . . . . . . . 956

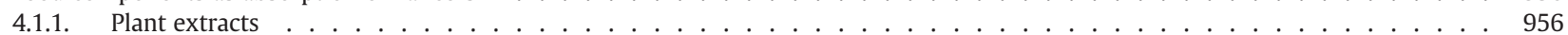

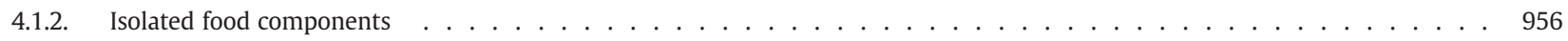

4.1.3. Miscellaneous . . . . . . . . . . . . . . . . . . . . . . . . . . . . . . . 9957

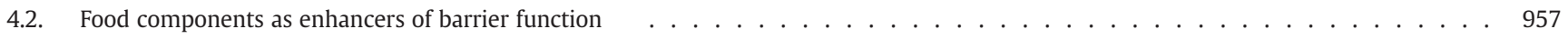

4.3. Phenolic compounds as modulators of intestinal permeability . . . . . . . . . . . . . . . . . . . . . . 958

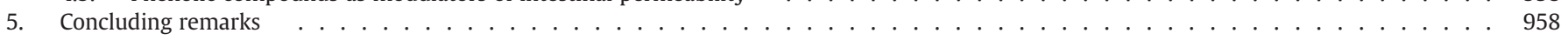

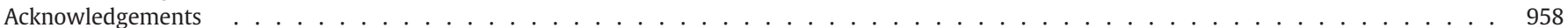

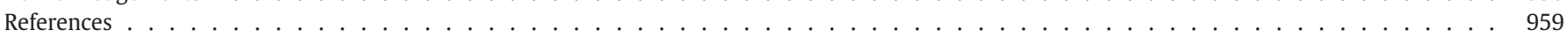

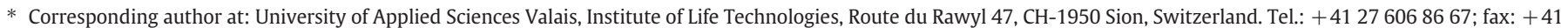
276068615

E-mail address: agnieszka.kosinska@hevs.ch (A. Kosińska). 


\section{Introduction}

The primary function of human intestine is to absorb nutrients and water. However, equally important is its ability to act as a selective barrier to protect the human system (Gropper, Smith, \& Groff, 2009). It serves as an effective defence against permeation of toxins, antigens and pathogens from the luminal environment into the circulatory system. The main constituents of intestinal epithelial cells are absorptive enterocytes (80\%), with enteroendocrine, goblet and Paneth cells making up the remaining 20\% (Schonhoff, Giel-Moloney, \& Leiter, 2004). The surface area of gut epithelium layer is heavily folded in so-called 'valves of Kerckring' and forms millions of finger-like villi. These features increase the surface area of the small intestine to $250 \mathrm{~m}^{2}$ allowing absorption of more nutrients than if it were smooth (Madara, 2011). The barrier role of the epithelial cells is dual. Fulfilling a gate function, it forms both a physical and biological obstacle. The physical barrier inhibits transport of microbes and larger molecules such as allergenic compounds, which cannot pass through the paracellular space. The biological barrier serves as a defence against xenobiotics due to expression of detoxification enzymes and efflux transporters. Crucial for barrier integrity is formation of tight junctions (TJs), protein complexes formed near the apical surface of the cells, sealing paracellular space between epithelial cells (Anderson \& Van Itallie, 2009; Farquhar \& Palade, 1963). In addition to the above described gate function, TJ serves as a fence, which hinders apical proteins from diffusing into the basal region and vice versa. Thus, it enables the maintenance of different compositions of integral membrane proteins as well as lipids in the apical and basolateral membrane domains. The third function of TJs, that has recently been acknowledged, is their role in signalling: signal recognition, transduction and response (GonzálezMariscal, Tapia, \& Chamorro, 2008; Terry, Nie, Matter, \& Balda, 2010; Van Itallie \& Anderson, 2006).

In recent years, it has been suggested that junctional complex has a highly dynamic structure (Raleigh et al., 2011; Shen, Weber, Raleigh, Yu, \& Tumer, 2011; Steed, Balda, \& Matter, 2010). The composition of TJ associated proteins is flexible and can be modulated by several factors. In this context, the effect of nutrients on epithelial barrier function has been reported (Hashimoto, Matsunaga, \& Shimizu, 1994; Isoda, Han, Tominaga, \& Maekawa, 2001; Sadowski \& Meddings, 1993; Suzuki, Tanabe, \& Hara, 2011; Ulluwishewa et al., 2011; Yasumatsu \& Tanabe, 2010). It is of vital importance to highlight that modulation of TJ could have dual implications. The increased permeability of intestinal epithelium has been linked to pathogenesis of inflammatory bowel disease, ulcerative colitis, Crohn's disease and food allergies. On the other hand, transient increase in paracellular transport could improve bioavailability of desirable bioactive compounds, which normally are poorly absorbed.

The purpose of this review is to compile and analyse the previous research investigating the possible relevance of food components to $\mathrm{TJ}$ regulation, with a special consideration of phenolic compounds.

\section{Intestinal absorption}

\subsection{Modes of intestinal absorption}

Enterocytes simultaneously serve as a protective barrier and facilitate transport of selected nutrients across the epithelium. Subsequently, nutrients diffuse into small blood vessels to provide nourishment to the organism. Molecules cross the intestinal epithelium by four main pathways, illustrated in Fig. 1. Firstly, by passive diffusion across the cell membranes. This transcellular diffusion involves mainly lipophilic compounds. Secondly, by carrier mediated transcellular transport of ions, glucose, amino acids, di- and tri-peptides. This is known as active transport and involves the action of two sets of transport proteins in the plasma membrane. One is present on the apical side of the cells and selectively transports molecules from the gut into the cell. The other set is located in the basolateral surfaces of the cells and facilitates the same molecules to diffuse into the extracellular fluid. The third mode of transport is a transcytosis of high-molecular-weight substances such as proteins which could be apically taken into the cell by endocytosis, intracellularly transported to the other side of the cell via the transcytotic vesicles and then released to the basolateral space by exocytosis (Shimizu, 1999). Finally, the fourth mode of absorption is passive diffusion between adjacent cells also called paracellular transport, mainly applicable to water-soluble low molecular weight compounds. The paracellular transport of compounds is regulated by the formation of a protein-protein network-epithelial junctional complex. This complex forms a physical barrier by mechanically linking adjacent cells and sealing intracellular space. Therefore, molecules cannot leak across the cell layer. However, the TJs are not sealed completely; they allow flow of some solutes and water. This passive movement through the space between adjacent cells, paracellular transport, is important in the absorption of amino acids, monosaccharides and small hydrophilic compounds, especially after a meal, when they are present in high concentration in the gut lumen (Déprez, Mila, Huneau, Tome, \& Scalbert, 2001; Sadowski \& Meddings, 1993).

\subsection{Permeability of $T J$}

TJs seal paracellular spaces of epithelium and thus create paracellular barriers that, depending on local transport requirements, differ in electrical conductance, ionic charge preference and the level of permeability for uncharged solutes (Van Itallie et al., 2008). These differences are referred to as permselectivity. The permeability of epithelia varies significantly between tissues; the epithelium of intestine is several orders of magnitude more permeable than the epithelium of skin, urinary bladder and stomach (Ballard, Hunter, \& Taylor, 1995; Farquhar \& Palade, 1963; Turner, 2000). In the intestine itself, permeability differs in the villus-crypt axis. The apical part of villus has a pore size of $6 \AA$, basal part of villus of $10 \AA$ and crypts as large as $60 \AA$ (Fihn, Sjoqvist, \& Jodal, 2000). Moreover, it can be regulated in response to pharmacological, physiological and pathophysiological status (Ballard et al., 1995; Lowe, Miyai, Steinbach, \& Hardison, 1988; Rodgers \& Fanning, 2011; Sadowski \& Meddings, 1993; Van Itallie, Fanning, Holmes, \& Anderson, 2010; Ward, Tippin, \& Thakker, 2000). Current information suggests that the paracellular barrier is most usefully explained as having two physiological components: a system of charge-selective small pores of $4 \AA$ in radius called a pore pathway, and a leak pathway lacking charge or size discrimination (leak pathway) (Shen et al., 2011; Van Itallie et al., 2008). The pore pathway is influenced by claudins expression patterns and carries large quantities of small uncharged solutes and specific ions. The leak pathway is likely controlled by different proteins and signals and allows small quantities of large molecules to pass (Anderson \& Van Itallie, 2009). The suitability of this model is confirmed by in vitro studies carried out in cell lines using polyethylene glycol oligomers of differentiated size. The results clearly showed that permeability is biphasic, consisting of a high-capacity and size-restrictive pore pathway as well as a low capacity and size-independent leak pathway (Linnankoski et al., 2010; Van Itallie, Fanning, Bridges, \& Anderson, 2009). Paracellular barrier function is commonly characterised by transepithelial electrical resistance (TEER). It measures ion conductance across the epithelial sheet at a given moment of time, therefore it reflects solely the permeability of small pores pathway. Additionally, the flux assay measuring the movement of large marker molecules, such as mannitol, inulin, Lucifer yellow (LY) or fluorescent dextrans over a period of time was used to measure permeability (Al-Sadi et al., 2011; Grube, Wolfrurn, \& Langguth, 2008; Noda, Tanabe, \& Suzuki, 2012; Van Itallie et al., 2009). 


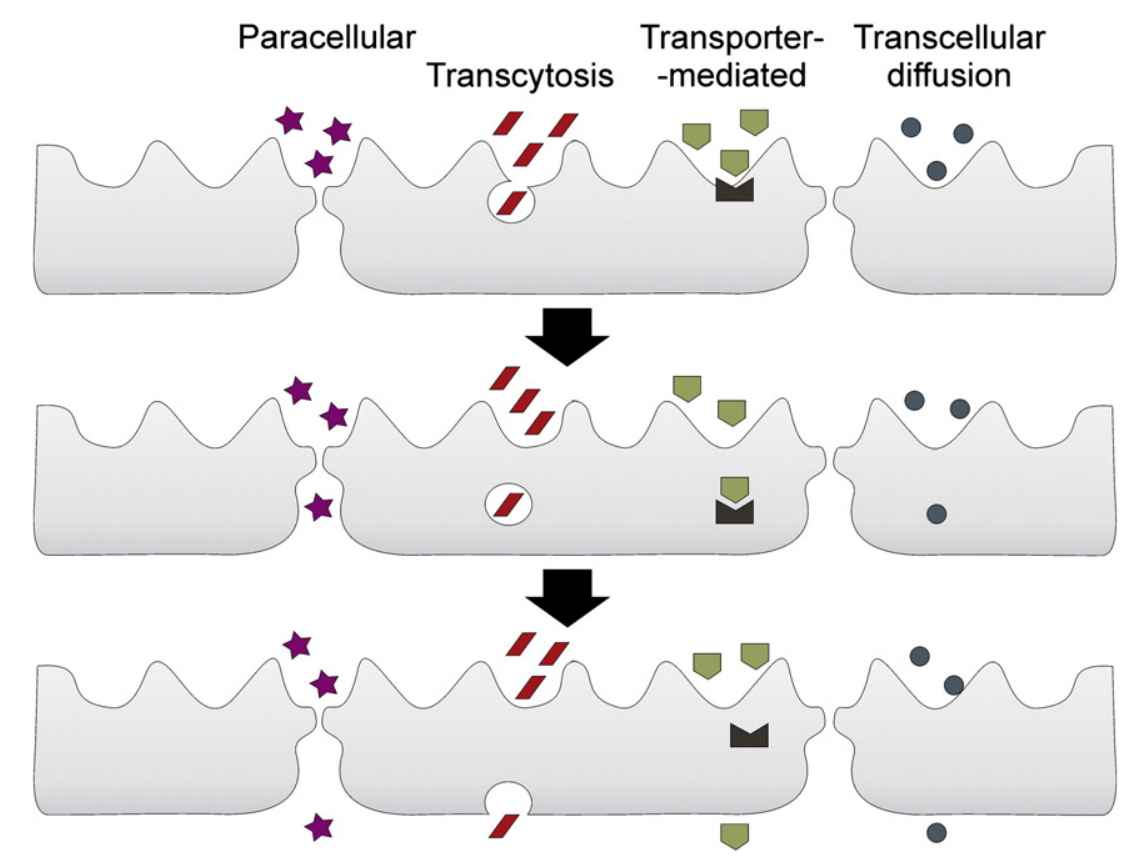

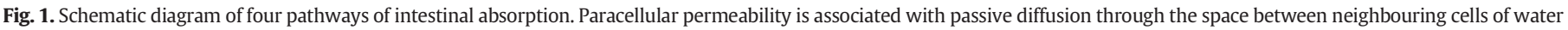

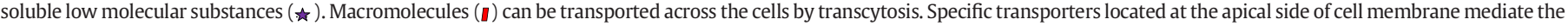
transport of specific nutrients ( $\square$ ). Hydrophobic substances (๑) can penetrate cell membrane and might be transported via cells interior by passive diffusion.

\subsection{Caco-2 cell model of intestinal epithelium}

The idea of developing an in vitro assay to study intestinal absorption emerged due to the boom in the drug discovery programmes of the seventies and eighties. Demand for quick and reliable model to evaluate intestinal permeability, more suitable for mimicking physiological conditions than those based on membrane partitioning, generated immense interest in developing cell based models. The attempts to either culture intestinal epithelial cells or to establish cell lines from enterocytes had been unsuccessful (Borchardt, 2011). Therefore, the attention was drawn to human colon adenocarcinoma cell lines. The first human colon carcinoma cell line HT-29 was established by Jorgen Fogh in 1964. A few years later the same author established Caco-2 (colon adenocarcinoma) line from the cells isolated from 72 years old Caucasian male (Fogh, Fogh, \& Orfeo, 1977). However, the discovery that those cells under specific culture conditions undergo differentiation into enterocytes was made several years later (Pinto et al., 1983). Caco-2 cells cultured for around 21 days form a polarised monolayer of differentiated enterocytes. During that time at an apical side of cells TJs are formed, as well as regular microvilli typical for a brush border in small intestine. The Caco-2 cells are also able to express a variety of brush border digestive enzymes, transporter proteins, efflux proteins, phase I and phase II enzymes and receptors (Hilgers, Conradi, \& Burton, 1990; Sun, Chow, Liu, Du, \& Pang, 2008). In order to better resemble the conditions of the intestine, Caco-2 cells are cultured on permeable filter supports placed in two chambers, representing apical and basolateral sides.

The mucus layer covering intestinal epithelium may form an additional barrier affecting the absorption. The lack of mucus production ability of Caco-2 cell line can be considered as its limitation. In order to overcome this problem, co-cultures of Caco-2 cells and HT29-H or HT29-MX were applied (Hilgendorf et al., 2000). Another disadvantage of the cell line is that the tightness of the monolayer resembles that of the colon and not the small intestine and therefore the permeability of paracellularly transported compounds can be underestimated. As Caco- 2 cell line is a heterogeneous population of cells, the properties of the cells may change with time in culture (Zweibaum, Laburthe, Grasset, \& Louvard, 2011). This may be an explanation for differences in morphology, expression of enzymes and transporters between laboratories (Sambuy et al., 2005). Moreover, culturing conditions strongly affect cell performance. Both factors may lead to highly variable results obtained in different laboratories and make the comparison of results very difficult. Thus, it needs to be emphasised that the attempts to develop a novel cell line, which will optimally mimic conditions of human small intestine, should be intensified.

Despite the above described limitations, Caco- 2 cell line is still considered to be the best model of intestinal absorption available up to now, showing the gene expression pattern closest to that of small intestinal enterocytes (Christensen et al., 2012). The model has emerged as one of the standard in vitro tools to predict in vivo intestinal absorption of various substances (Langerholc, Maragkoudakis, Wollgast, Gradisnik, \& Cencic, 2011; Xie, Kosińska, Xu, \& Andlauer, 2012). Moreover, Caco-2 cell model is widely utilised to identify and elucidate the mechanisms of TJ modulation (Al Sadi \& Ma, 2007; Suzuki \& Hara, 2004).

\section{Structure of $\mathrm{TJ}$}

Protein complexes connecting epithelial cells include TJs, gap junctions, adherens junctions (AJ) and desmosomes. TJs are typically located at the apical side, whereas AJs and desmosomes are located within the basolateral membrane (Hartsock \& Nelson, 2008). Desmosomes and AJ are involved in cell-cell adhesion (Runswick, O'Hare, Jones, Streuli, \& Garrod, 2001), whereas gap junctions take part in intracellular communication (Kumar \& Gilula, 1996). The junctional complexes encircle the cells resulting in a continuous belt that interconnects neighbouring cells.

In order to understand the molecular mechanism controlling $\mathrm{TJ}$ structure and function, it is important to determine their molecular composition and organisation. The last 30 years of intensive research in this field has allowed characterisation of the main molecular components and has given a new insight into their interactions and mechanisms that regulate $\mathrm{TJ}$ functions. At least 40 different proteins are involved in TJ formation (Furuse, 2010). They play many interrelated roles in cell polarity, signalling, transcriptional regulation, cell cycle, vesicle trafficking in addition to formation of the paracellular barrier (Balda \& Matter, 2008). The schematic structure of TJ is presented in Fig. 2, whereas the structural features and major functions of TJ associated proteins are compiled in Table 1. 


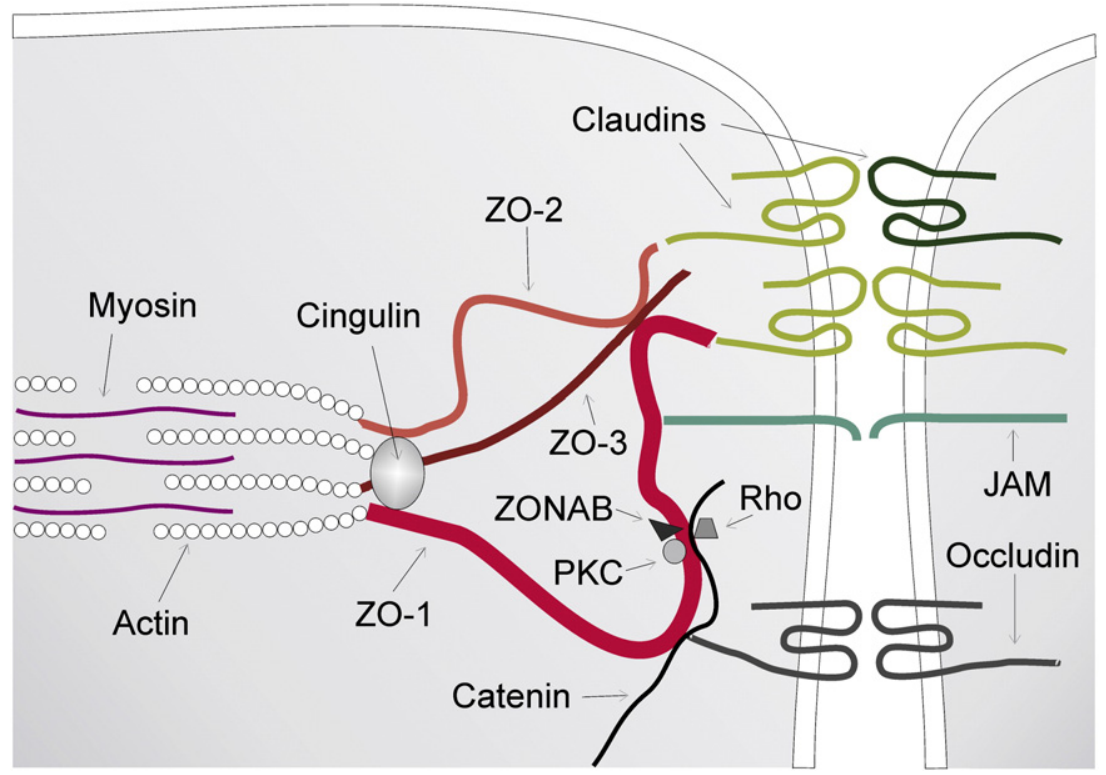

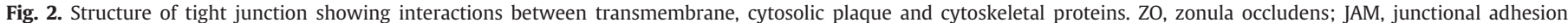
molecule; PKC, protein kinase C; Rho, family of small GTPases; ZONAB, zonula occludens-1 associated nucleic acid binding protein.

\subsection{Integral membrane proteins}

Integral membrane proteins comprise occludin, claudins, junctional adhesion molecules (JAMs) and tricellulin. These transmembrane proteins are linked to cytoplasmic plaque proteins, among which zonula occludens ( $\mathrm{ZO}$ ) and cingulin are the most important for the integrity of the epithelial barrier since they anchor transmembrane proteins to the perijunctional actin myosin ring (PAMR). Transmembrane proteins mediate cell to cell adhesion and can be divided into tetraspan proteins (containing four transmembrane domains) and singlespan proteins. Occludin, claudins and tricellulin are tetraspan proteins, whereas single-span transmembrane proteins are mainly JAMs.

In humans, claudins constitute a family of more than 20 members. It has been recently discovered that claudins are the main proteins responsible for regulation of epithelial paracellular transport (Furuse, 2010; Van Itallie \& Anderson, 2006; Yamazaki, Tokumasu, Kimura, \& Tsukita, 2011). Claudins (tetraspanning membrane proteins) have two extracellular loops, and $\mathrm{N}$ - and C-terminal cytoplasmic domains (Lal-Nag \& Morin, 2009). Extracellular loops are critical for homophilic (between identical protein) and/or heterophilic (between nonidentical proteins) interactions and the formation of ion selective channels. The C-terminal cytoplasmic domain contains a PDZ domain binding motif. Claudins interact with the PDZ-domain of cytosolic proteins, including ZO-1, ZO-2, and ZO-3, which anchor claudins to the cytoskeleton. PDZ is an acronym derived from first letters of names of proteins first discovered to share this domain i.e. Post synaptic density 95, Disc large and ZO-1 domain. Claudin-claudin interactions between adjacent cells can be either homophilic or heterophilic. The intracellular C-terminal domain of claudin possesses multiple regulatory sites, including serine and threonine phosphorylation sites (Lal-Nag \& Morin, 2009). Signalling pathways including protein kinase C (PKC), Rho guanosine triphosphatases (Rho GTPases), mitogen-activated protein kinases (MAPKs) and phosphatases are involved in the regulation of these phosphorylation sites (Van Itallie \& Anderson, 2006).

Claudins are key components for the structure and function of TJs. They are responsible for cation- and anion-selective pores formation and ion flux, measurable by TEER. It has been proposed that the extracellular loops of claudins can create selective paracellular pores, that allow passive diffusion of ions (Van Itallie \& Anderson, 2006; Van Itallie et al.,
2008). The profile and level of different claudins are critical determinants of permselectivity of TJ (Yu, 2009). The modulation of expression of distinct members of claudin family may change the permeability and charge selectivity of paracellular route in different directions (Vreeburg, van Wezel, Ocana-Calahorro, \& Mes, 2012). Claudins can be classified according to the function as sealing and pore forming. Expression of claudin-2 selectively increases the permeability for solutes smaller than $4 \AA$, whereas claudin-1, $-3,-4,-5$ and -8 tighten TJ (Colegio, Van Itallie, Mccrea, Rahner, \& Anderson, 2002; Schulzke, Gunzel, John, \& Fromm, 2012; Van Itallie et al., 2008).

Occludin is a second tetraspan membrane protein with 2 extracellular loops, a short cytoplasmic N-terminus and a long cytoplasmic C-terminus. The C-terminus interacts with the PDZ domain of ZO-1. This connection is essential in linking occludin to the actin cytoskeleton. A role of occludin in the regulation of paracellular permeability has been suggested (Raleigh et al., 2011). Its localisation in TJ complex is regulated by reversible phosphorylation catalysed by kinases and phosphatases (Tsukamoto \& Nigam, 1999). Phosphorylation and dephosphorylation of occludin is a crucial post-translational modification since it is connected to assignment of occludin to different subcellular compartments. Kinases and phosphatases involved are expected to be major players in the assembly-disassembly process. Associations between extracellular loops of occludin and claudin are important for barrier formation. It has been suggested that occludin plays a role in the regulation of flux of large macromolecules, presumably through the non-restrictive leak pathway (Al-Sadi et al., 2011). Nevertheless, occludin phosphorylation also modifies permeability of claudin based pores (Raleigh et al., 2011).

Tricellulin is an important component at a meeting point of three cells. Like claudin and occludin, tricellulin is also a tetraspan protein with two extracellular loops. It is localised at the TJ strand of tricellular contacts of epithelial cells and exhibits a partial homology with occludin in the region responsible for its binding to ZO-1 (Mariano, Sasaki, Brites, \& Brito, 2011).

The last class of integral membrane proteins comprises members of immunoglobulin superfamily proteins and includes JAM and coxsackie and adenoviral serotype 2/5 receptor (CAR) (Martín-Padura et al., 1998). JAM has one $\mathrm{N}$-terminal extracellular region (containing two extracellular Ig-like domains), one transmembrane region and one C-terminal cytoplasmic tail with a PDZ-binding motif. The JAM-PDZ interaction anchors 
Table 1

Tight junction (TJ) associated proteins.

\begin{tabular}{|c|c|c|}
\hline Name & Structural features & Major functions \\
\hline \multicolumn{3}{|l|}{ Transmembrane proteins } \\
\hline Claudins & $\begin{array}{l}\text { Four transmembrane domains, two extracellular loops, two cytoplasmic } \\
\text { tails, one PDZ binding motif }\end{array}$ & Cell-cell adhesion; cation and anion selective pores formation \\
\hline Occludin & $\begin{array}{l}\text { Four transmembrane domains, two extracellular loops, short cytoplasmic } \\
\text { N-terminus and long cytoplasmic C-terminus, one PDZ binding motif }\end{array}$ & Cell-cell adhesion; regulation of flux of macromolecules \\
\hline Tricellulin & Homologous to occludin & Cell-cell adhesion; critical for assembly of three cells \\
\hline $\begin{array}{r}\text { Junctional adhesion } \\
\text { molecules (JAMs) }\end{array}$ & $\begin{array}{l}\text { Immunoglobulin superfamily, one N-terminal extracellular region } \\
\text { containing two Ig domains, one transmembrane region, one C-terminal } \\
\text { cytoplasmic tail with PDZ binding motif }\end{array}$ & $\begin{array}{l}\text { Cell-cell adhesion; anchors TJ to actin cytoskeleton through } \\
\text { binding to ZO-1 }\end{array}$ \\
\hline $\begin{array}{l}\text { Coxsackie and adenoviral } \\
\text { serotype receptor (CAR) }\end{array}$ & $\begin{array}{l}\text { Immunoglobin superfamily, single membrane spanning domain, } \\
\text { PDZ binding motif }\end{array}$ & $\begin{array}{l}\text { Mediates cell-cell binding, interacts with ZO-1 } \\
\text { (directly or indirectly), MAGI-1 and MUPP1 }\end{array}$ \\
\hline \multicolumn{3}{|l|}{ Cytoplasmic plaque proteins } \\
\hline Zonula occludens (ZO-1-3) & $\begin{array}{l}\text { Three PDZ domains, one SH3 domain, one GUK domain, one actin-binding } \\
\text { region }\end{array}$ & $\begin{array}{l}\text { ZO- } 1 \text { is the central structural protein of the tight junction, } \\
\text { serves as intracellular scaffold, ZO- } 1-3 \text { associate } \\
\text { transmembrane proteins to cytoskeleton and signalling } \\
\text { molecules; ZO-1 depletion increases flux of macromolecules }\end{array}$ \\
\hline Cingulin & $\begin{array}{l}\text { Homodimer, each subunit contain globular N-terminal head, long } \\
\text { coiled-coil rod and C-terminal tail }\end{array}$ & Interacts with ZO-1, actin and myosin \\
\hline $\begin{array}{l}\text { Membrane associated guanylate } \\
\text { kinase inverted (MAGI) }\end{array}$ & 6 PDZ-domains, one GUK domain & Scaffolding molecule \\
\hline $\begin{array}{l}\text { Multi-PDZ domain protein } 1 \\
\text { (MUPP1) }\end{array}$ & 13 PDZ-domains & Binds to claudin- 1 and JAM \\
\hline Partitioning proteins (PAR-3/-6) & 10 PDZ-domains & Binds to JAM \\
\hline
\end{tabular}

PDZ, Post synaptic density 95, Disc large and ZO-1 domain; GUK, guanylate kinase domain.

TJ to the actin cytoskeleton, by binding to ZO-1 and cingulin. Extracellular homophilic and heterophilic interactions of JAMs are responsible for paracellular permeability.

\subsection{Cytoplasmic plaque proteins}

In addition to the integral membrane proteins, TJs are formed by several peripheral proteins localised in the cytoplasm and comprising adaptor/scaffolding proteins, signalling molecules and transcriptional regulators. Adaptor proteins form the link between the integral membrane proteins and cytoskeleton. Many members of this group of proteins contain PDZ domains, which enable multiple protein-protein interactions. ZO-1, ZO-2 and ZO-3 are members of the membrane associated guanylate kinase (MAGUK) family proteins. They share characteristic features of all MAGUK proteins: PDZ domains and an SH3 domain, as well as a carboxyl terminal containing an acidic domain and proline-rich regions. Due to their modular organisation, they function as scaffolds; they bind to transmembrane TJ proteins, the cytoskeleton and signal transduction molecules. The central role of ZO-1 in protein-protein interaction is illustrated in Fig. 3. ZO-1 interacts with claudins through its first PDZ domain, with ZO-2 or ZO-3 through its second PDZ domain, with occludin and tricellulin through the guanylate kinase (GUK) homology domain and with F-actin and $\alpha$-catenin through its large C-terminal domain. In addition, via its $\mathrm{SH} 3, \mathrm{ZO}-1$ domain binds to several signalling proteins such as a serin/threonine protein kinase, heat shock protein Apg2, transcription factor ZONAB (ZO-1 associated nucleic acid binding protein), and therefore regulates gene transcription and cell proliferation (Van Itallie et al., 2009). ZOs shuttle between the TJ and the nucleus, where they may regulate gene expression. The role of ZO-1 in paracellular permeability was revealed by Van Itallie et al., who found that ZO-1 depletion increases flux in the leak pathway for solutes larger than claudin pore. At the same time it does not decrease TEER values, which means that the flux through pore pathway remains unchanged (Van Itallie et al., 2009).

ZO-1 incorporates cingulin to TJ. Cingulin has a globular head domain and a coiled coil domain. It also interacts with ZO-2, ZO-3, JAM, actin and myosin (Assimakopoulos, Papageorgiou, \& Charonis, 2011). In addition to ZO 1-3, several PDZ domain containing proteins such as membraneassociated guanylate kinase inverted (MAGI-1, MAGI-2, MAGI-3),
multi-PDZ domain protein 1 (MUPP1), partitioning-defective (PAR-3 and PAR-6) and PALS-1-associated tight junction (PATJ) proteins are involved in TJ formation (Hamazaki, Itoh, Sasaki, Furuse, \& Tsukita, 2002). The roles of the above mentioned proteins are still under investigation; however, their association with T]s has been confirmed.

Cytoplasmic plaque proteins also recruit regulatory and signalling proteins to TJ. Signalling molecules involved in TJ formation play a role in maintenance of epithelial barrier integrity. They include the Rho family of small GTPases, protein kinases and protein and lipid phosphatases, amongst others (Terry et al., 2010). In addition, transcription

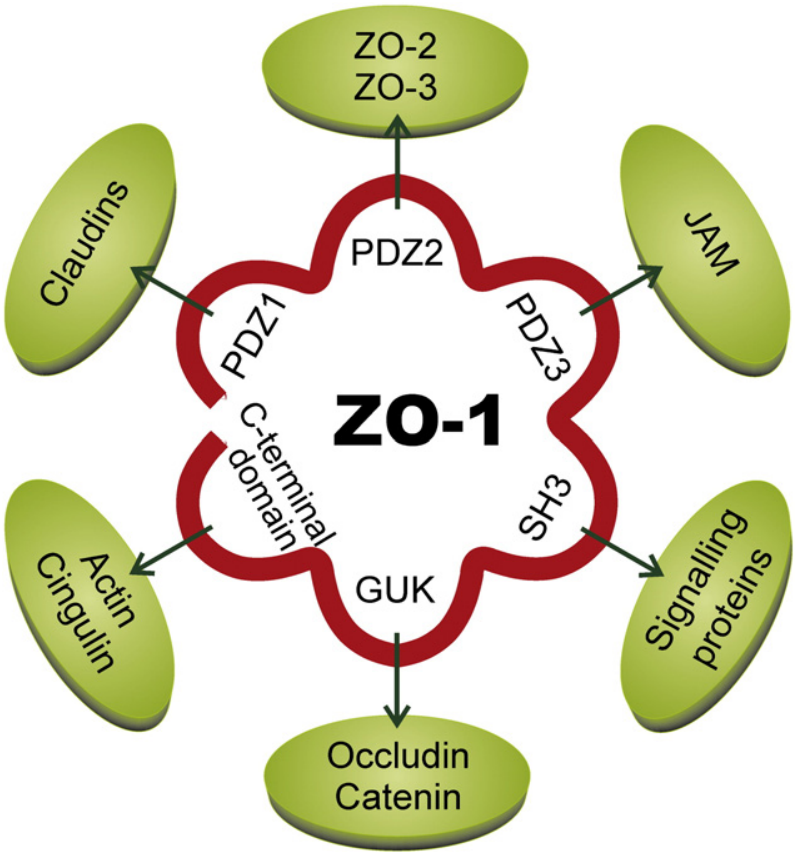

Fig. 3. Schematic diagram of interactions of ZO-1 (zonula occludens-1) with transmembrane, cytosolic and cytoskeletal proteins. JAM, junctional adhesion molecule; PDZ, Post synaptic density 95, Disc large and ZO-1 domain; SH3, Src homology domain; GUK, guanylate kinase domain. 
factors are also associated to TJs by scaffolding proteins i.e. ZONAB, a transcription factor involved in cell growth.

\subsection{Cytoskeletal proteins}

ZO-1, ZO-2, ZO-3 and cingulin bind to F-actin. The actin cytoskeleton, in association with myosin II, forms a belt encircling the cell, known as PAMR (Rodgers \& Fanning, 2011).

\subsection{Adherens junctions}

AJs are formed by interactions between transmembrane proteins, intracellular adaptor proteins and the cytoskeleton. The predominant interactions are the cadherin-catenin interactions. The calcium dependent adhesion molecules, E-cadherins, are single transmembrane spanning glycoproteins with intracellular C-terminus and extracellular $\mathrm{N}$-terminus. The extracellular domain forms homotypical interactions with the cadherin of neighbouring cells. The intracellular domain of cadherin binds to catenin, which links the AJ to the cytoskeletal network. It is possible that this is achieved by a direct binding to the C-domain of F-actin or indirectly through interactions with another adaptor protein, specifically, afadin. Cadherin-catenin complexes are important for linking adjacent cells but also for maintaining cell polarity, regulating epithelial migration and proliferation (Hartsock \& Nelson, 2008).

\section{Modulation of $\mathrm{TJ}$}

TJ has a dynamic and complex multiprotein structure. The modulation of paracellular permeability must always be considered from two distinct points of view. Firstly, TJs play an important role in the pathogenesis of Crohn's disease, inflammatory bowel disease, ulcerative colitis and food allergies, and TJ can tighten for the therapeutic reason of diminishing the risk of disease onset (Assimakopoulos et al., 2011; Förster, 2008; Groschwitz \& Hogan, 2009). Secondly, intentional opening of paracellular space can be applied to increase the absorption of poorly permeable drugs and bioactive compounds (Deli, 2009; Kang, Cho, Shim, Kim, \& Lee, 2009; Salama, Eddington, \& Fasano, 2006; Ward et al., 2000). TJ is selectively permeable to certain hydrophilic molecules. The paracellular route of absorption is much less efficient than any other pathway. However, increased paracellular permeability could be of vital importance for enhancing absorption of a wide range of poorly absorbed drugs and food substances.

The permeability of $\mathrm{TJ}$ is physiologically regulated (Ballard et al., 1995). It can be affected by both intracellular and extracellular events. Intracellular stimuli are related to energy depletion and cAMP level changes. ATP depletion downregulates TJs, whereas cAMP reduces paracellular permeability. Extracellular events include interactions with other cellular proteins, interaction to external antigens, cytokines, oxidative stress, calcium level imbalance, amongst others (Steed et al., 2010). The intestinal TJs are more permeable after a meal, presumably in order to allow hydrophilic nutrients like glucose and amino acids to pass through paracellular spaces. The change in permeability is probably induced by PAMR contractions (Rodgers \& Fanning, 2011). Furthermore, cytokines, such as tumour necrosis factor $\alpha$ (TNF $\alpha$ ), interferon gamma (IFN $\gamma$ ), hepatocyte growth factor (HGF), interleukin 4 (IL-4) and 13 (IL-13) have been reported to decrease barrier function (Al Sadi \& Ma, 2007; Juuti-Uusitalo et al., 2011). Even the presence of nutrients such as glucose and alanine increases permeability of high molecular weight markers (Sadowski \& Meddings, 1993). This observation has led to the presumption that due to its continuous exposure to food components, functions of the intestinal epithelium might be affected or even regulated by food substances.

Numerous studies have demonstrated that the tightness of cultured epithelial monolayers can be increased or decreased by changing the expression profiles of specific protein components of the TJ
(Al-Sadi et al., 2011; González-Mariscal et al., 2008; Noda et al., 2012; Raleigh et al., 2011). Once the structure and role of individual $\mathrm{TJ}$ proteins was revealed, it became possible to intentionally alter their functioning. This can be achieved by down or up regulation of specific genes responsible for the expression of individual TJ proteins, or affecting signalling pathways. It has been reported that a pore pathway is dependent on claudin expression, whereas flux through a leak pathway is sensitive to cytoskeletal disruption and can be enhanced by proinflammatory cytokines without altering the pore pathway (Anderson \& Van Itallie, 2009; Shen et al., 2011). Signalling pathways involved in TJ regulation, and interactions between transmembrane proteins and the PAMR are controlled by several signalling proteins including PKC, MAPK, MLCK and the Rho family of small GTPases. Phosphorylation of TJ proteins and displacement (contraction or relaxation) of the PAMR have been shown to affect epithelial barrier function (Ward et al., 2000).

\subsection{Food components as absorption enhancers}

\subsubsection{Plant extracts}

Screening studies of food extracts to determine their effect on TJ integrity have been carried out. Table 2 compiles data of food related modulators of TJ, both enhancing and decreasing epithelial permeability. As early as in 1994 Hashimoto et al. examined aqueous extracts of 32 different kinds of vegetable (Hashimoto et al., 1994). From this vast selection, only sweet pepper and ginger extract significantly decreased the TEER values. However, in this study the effect on LY flux was not evaluated. It should be mentioned that ginger reduced viability of the cells whereas sweet pepper did not. Thus, only sweet pepper extract was suggested to contain substances that increase the TJ permeability without exerting cytotoxic effect on cells. More than 300 food materials such as vegetables, fruits, seaweeds, teas, spices, and other edible plants were examined by Konishi in the context of their effect on TEER value and LY flux (Konishi, 2003). Aqueous extracts of galangal, marigold, Nikko maple and hops were able to decrease TEER and simultaneously increase LY flux, without exerting adverse effects on cell viability. However, linden, star anise, black tea and dwarf sugar palm extracts strengthened the barrier integrity. Unfortunately, quite often the effect of food components on intestine permeability was not the main objective of the studies carried out, and the results available resulted from side observations, which were not further approached. In the course of absorption studies some authors noticed considerably lowered TEER values as a result of the application of food components or extracts on Caco-2 cell monolayers. However, the reasons and mechanisms of this phenomenon were not further studied. Digested tomato and mango juice as well as dried tomato, mango and papaya caused significant decreases in the TEER values (Epriliati, D'Arcy, \& Gidley, 2009). Also Laitinen et al. (2004) reported that herb extracts affected paracellular diffusion of compounds through Caco-2 monolayers. The authors suggested that the herb extracts caused partial opening of paracellular spaces between Caco- 2 cells. At the same time no effect of bilberries, cowberries, and raspberry phenolic compound extracts on Caco-2 TEER was observed. Similarly, the addition of grapefruit juice did not affect Caco-2 monolayer integrity measured by TEER, whereas pummelo juice addition increased TEER value and lime and lemon juices addition resulted in a drop of TEER associated with decreased cell viability (Xu, Go, \& Lim, 2003). Ginger, carrot and shimeji (edible mushroom) aqueous extracts decreased TEER value by 40 50\% without toxic effects (Eguchi, Murakami, \& Ohigashi, 2005).

\subsubsection{Isolated food components}

Lectins isolated from Japanese jack bean and wheat germ resulted in significantly decreased TEER values and increased calcium ions, isoflavones and quercetin glycosides transport across epithelium (Ohno, Naganuma, Ogawa, \& Muramoto, 2006). Capsaicin, a major 
Table 2

Food related modulators of tight junction integrity.

\begin{tabular}{|c|c|c|c|c|}
\hline Modulating substance & Concentration & Effect on TEER value & Effect on macromolecule flux & Reference \\
\hline \multicolumn{5}{|l|}{ Plant extracts } \\
\hline Sweet pepper & $5 \mathrm{mg} / \mathrm{mL}$ & $\downarrow$ & n.e. & Hashimoto et al. (1994) \\
\hline Galangal, marigold, maple Nikko, hops & $5 \mathrm{mg} / \mathrm{mL}$ & $\downarrow$ & $\uparrow L Y$ & Konishi (2003) \\
\hline Linden, star anise, black tea, dwarf sugar palm & $5 \mathrm{mg} / \mathrm{mL}$ & $\uparrow$ & $\downarrow$ & Konishi (2003) \\
\hline $\begin{array}{l}\text { Mango juice, dried tomato, mango, } \\
\text { papaya digests }\end{array}$ & - & $\downarrow$ & $\uparrow$ mannitol & Epriliati et al. (2009) \\
\hline Sage, rosemary, oregano & $1 \mathrm{mg} / \mathrm{mL}$ & $\downarrow$ & $\uparrow$ mannitol & Laitinen et al. (2004) \\
\hline Ginger, carrot and shimeji & $0-25 \%$ & $\downarrow$ & n.e. & Eguchi et al. (2005) \\
\hline Aloe leaves & $0.5-2.0 \%$ & $\downarrow$ & $\uparrow$ atenolol, $\uparrow$ FITC dextran & Chen et al. (2009); Lebitsa et al. (2012) \\
\hline Apple extract and digest & - & $\uparrow$ & n.e. & Vreeburg et al. (2012) \\
\hline \multicolumn{5}{|l|}{ Isolated food components } \\
\hline Lectins & $0-180 \mu \mathrm{g} / \mathrm{mL}$ & $\downarrow$ & n.e. & Ohno et al. (2006) \\
\hline Capsaicin & $100-500 \mu \mathrm{M}$ & $\downarrow$ & n.e. & Isoda et al. (2001); Tsukura et al. (2007) \\
\hline Taurine & $0.5-2.0 \%$ & $\downarrow$ & n.e. & Cho et al. (2002) \\
\hline Sinomenin & $0.5-2.0 \%$ & $\downarrow$ & n.e. & Lu et al. (2010) \\
\hline Nondigestible saccharides & $50-100 \mathrm{mM}$ & $\downarrow$ & $\uparrow \mathrm{LY}$ & Suzuki and Hara (2004); Suzuki et al. (2010) \\
\hline Glutamine & - & $\uparrow$ & n.e. & Li et al. (2004) \\
\hline Curcumin & $5 \mu \mathrm{M}$ & $\uparrow$ & n.e. & $\begin{array}{l}\text { Al Sadi and Ma (2007); Rapin and } \\
\text { Wiernsperger (2010) }\end{array}$ \\
\hline Casein peptide & $0.001-0.1 \mathrm{mM}$ & $\uparrow$ & n.e. & Yasumatsu and Tanabe (2010) \\
\hline Sodium caprate & $10 \mathrm{mM}$ & $\uparrow$ & n.e. & Soderholm et al. (1998) \\
\hline \multicolumn{5}{|l|}{ Phenolic compounds } \\
\hline Chrysin & $100 \mu \mathrm{M}$ & $\downarrow$ & $\uparrow$ FITC dextran & Noda et al. (2012) \\
\hline $\begin{array}{l}\text { Luteolin, daidzein, genistein, hesperetin, } \\
\text { naringenin, morin }\end{array}$ & $100 \mu \mathrm{M}$ & $\uparrow$ & $\sim$ FITC dextran & Noda et al. (2012) \\
\hline Ferulic, isoferulic and $p$-coumaric acids & $20-100 \mu \mathrm{M}$ & $\uparrow$ & n.e. & Bergmann et al. (2009) \\
\hline ECG & $50-200 \mu \mathrm{M}$ & $\downarrow$ & $\uparrow$ mannitol & Vaidyanathan and Walle (2003) \\
\hline Green tea extract & $276 \mu \mathrm{g} / \mathrm{mL}$ & $\downarrow^{\mathrm{a}}$ & n.e. & Zhang et al. (2006) \\
\hline EC and EGC & $>300 \mu \mathrm{M}$ & $\downarrow$ & n.e. & Chan et al. (2007) \\
\hline A-type procyanidins from cranberries & $0.3-1 \mathrm{mM}$ & $\downarrow$ & n.e. & Ou et al. (2012) \\
\hline Hexameric procyanidins & $20 \mu \mathrm{M}$ & $\uparrow$ & n.e. & Erlejman et al. (2006) \\
\hline Procyanidins & $1 \mathrm{mM}$ & $\uparrow$ & n.e. & Déprez et al. (2001) \\
\hline Quercetin, quercitrin & $100-200 \mu \mathrm{M}$ & $\uparrow$ & $\sim$ mannitol & Amasheh et al. (2008); Suzuki and Hara (2009) \\
\hline Quercetin, myrecitin & $10-100 \mu \mathrm{M}$ & $\uparrow$ & $\downarrow$ LY & Suzuki and Hara (2009) \\
\hline Kaempferol & $10-100 \mu \mathrm{M}$ & $\uparrow$ & $\sim$ LY, FITC dextran & Suzuki et al. (2011) \\
\hline
\end{tabular}

EC, epicatechin; ECG, epicatechin gallate; EGC, epigallocatechin; FITC dextran, fluorescein isothiocyanate dextran; LY, lucifer yellow; TEER, transepithelial electrical resistance. $\downarrow$ decrease.

$\uparrow$ increase.

$\sim$ not influenced.

n.e. not evaluated.

${ }^{a}$ In the case of secretion transport.

component of hot pepper caused reversible opening of the paracellular route (Isoda et al., 2001; Tsukura et al., 2007). Taurine, naturally occurring in meat and seafood, decreased TEER value and enhanced transport of heparin disaccharide. It has been suggested that it affected the level of intercellular $\mathrm{Ca}^{2+}$, which plays a role in regulation of $\mathrm{TJ}$ by activation of protein kinase C (Cho et al., 2002). Sinomenine, an alkaloid extracted from the stem of Sinomenium acutum, significantly decreased TEER values. Therefore, transepithelial transport of vitamin C, luteolin, rutin and insulin was significantly increased. This effect was rapidly reversed after removal of sinomenine (Lu, Chen, Viljoen, \& Hamman, 2010).

Leaves of two aloe species increased TEER values as well as transport of atenolol (Chen, Lu, Viljoen, \& Hamman, 2009; Lebitsa, Viljoen, Lu, \& Hamman, 2012). The ability to open TJ was assigned to polysaccharides present in aloe. It is worth mentioning that the opening was fully reversible. Nondigestible saccharides have also been reported to increase paracellular absorption of $\mathrm{Ca}^{2+}$ both in Caco-2 model (Suzuki \& Hara, 2004) and in the small intestine of rat (Suzuki et al., 2010). The mechanism of action was studied in the second case, and it was reported that epilactose activates paracellular $\mathrm{Ca}^{2+}$ absorption through the induction of MLC phosporylation and thus, contractions of the PAMR in the intestinal cells.

\subsubsection{Miscellaneous}

Yeast cells have been reported to increase the permeability of Caco-2 cell monolayers in a non-toxic and reversible manner (Fuller, Duckham,
\& Wood, 2007). The suggested mode of action was linked with translocation of ZO-1 and occludin associated proteins from the membrane to cytoskeletal cell areas, which could involve protein kinase $\mathrm{C}$ activation.

\subsection{Food components as enhancers of barrier function}

Glutamine and curcumin have been reported to have a therapeutic effect on 'leaky gut' syndrome, by decreasing paracellular permeability (Rapin \& Wiernsperger, 2010). Deprivation of glutamine decreased claudin-1, occludin, and ZO-1 protein expression (Li, Lewis, Samuelson, Liboni, \& Neu, 2004). However, at the same time, a disappearance of perijunctional claudin- 1 and a reduction of occludin was observed, but surprisingly no effect on ZO-1 was reported. In turn, curcumin prevented IL-1 $\beta$ induced changes in intestinal epithelial permeability (Al Sadi \& Ma, 2007). The effect of apple digest and crude extract on Caco-2 barrier function was investigated by Vreeburg et al. (2012). They observed an increase in paracellular resistance of the Caco-2 monolayer, which was not evoked by phosphokinase A, phosphokinase $C$, phosphokinase $G$, myosin light chain kinase or intracellular calcium signalling. The authors concluded that increase in resistance was due to increased expression of claudin-4. Another study demonstrated that casein peptide Asn-ProTrp-Asp-Gln enhanced epithelial barrier function (TEER) due to the ability to up-regulate occludin expression (Yasumatsu \& Tanabe, 2010). 


\subsection{Phenolic compounds as modulators of intestinal permeability}

Phenolic compounds are mainly found in fruits, vegetables and cereals, as well as in tea and wine (Aaby, Ekeberg, \& Skrede, 2007; Kosińska et al., 2012; Wu, Xu, Héritier, \& Andlauer, 2012). Their health benefits have been widely studied, and attributed mainly to their antioxidant activities (Blomhoff, Carlsen, Andersen, \& Jacobs, 2006; Boyer \& Liu, 2004; Seeram, 2008; Seeram et al., 2006). However, in recent years, it has been pointed out that they usually occur in systemic circulation at a concentration much lower than required for effective antioxidant activity. Thus, it has been acknowledged that their biological functions are mainly related to their ability to affect enzyme activities as well as signalling molecules, nuclear receptors and gene expression (Gonzalez et al., 2011; Sharma et al., 2010; Son, Camandola, \& Mattson, 2008; Vreeburg, Bastiaan-Net, \& Mes, 2011; Weinreb, Amit, Mandel, \& Youdim, 2009). Accordingly, the ability of phenolic compounds to affect TJ functioning can be assumed. In general, phenolic compounds cannot be easily classified as permeability or barrier function enhancers, since they may exert both effects on barrier integrity.

Phenolic acids, such as ferulic, isoferulic and $p$-coumaric acids have been found to increase initial TEER values of colon epithelial cell monolayers (Bergmann, Rogoll, Scheppach, Melcher, \& Richling, 2009). Flux of macromolecular marker was not measured. Moreover, the above mentioned phenolic acids, their respective esters (4-p-coumaroylquinic acid, 1-caffeoylquinic acid, and 5-caffeoylquinic acid) and investigated flavonoids such as quercetin, quercetin 3-O-rhamnoside, phloretin, phloretin 2'-O-glucoside, and phloretin 2'-O-xyloglucoside besides the flavan-3-ols such as (-)-epicatechin and $(+)$-catechin were able to reverse the TJ opening effect of capric acid. The authors reported direct induction of the expression of genes encoding the TJ components: ZO-1, occludin and claudin- 4 by ferulic and isoferulic acids.

The effect of seven flavonoids: chrysin, luteolin, daidzein, genistein, hesperetin, naringenin, and morin on TJs was investigated by Noda et al. (Noda et al., 2012). Chrysin enhanced transepithelial permeability which was reflected by decreased TEER and at the same time increased flux of conjugated dextran of average molecular weight of $4000 \mathrm{Da}$. It was consistent with the effect of chrysin on TJ protein expression i.e. occludin, JAM-1 and claudin-1, -3 and -4 in the cells incubated with chrysin was lower than in control cells. On the contrary, daidzein, hesperetin, morin and naringenin significantly increased TEER, but showed no significant change of dextran flux. Genistein and luteolin normalised TEER after its transient decrease. The effect of quercetin and myricetin on epithelial barrier properties was demonstrated by Suzuki and Hara (2009). Both compounds increased TEER of Caco-2 monolayers and lowered LY flux. Quercetin enhanced barrier function through the assembly of ZO-2, claudin-1 and occludin resulting from direct inhibition of PKC $\delta$. The activity of PKC isoforms plays a role in phosphorylation of TJ proteins, which is one of the most potent ways of influencing TJ functioning (Deli, 2009; Ward et al., 2000). Also Amasheh et al. reported enhanced barrier properties of Caco-2 cell monolayers as a result of quercetin and quercetrin treatment (Amasheh et al., 2008). However, the observed effect was brought about by induced claudin- 4 expression. At the same time, claudin-1, $-3,-7$ and occludin expression remained unchanged. Similarly, kaempferol-mediated increment of TEER has been related to the promotion of the cytoskeletal association and expression of ZO-1, ZO-2, occludin, claudin-1, claudin-3, and claudin-4 (Suzuki et al., 2011).

Vaidyanathan and Walle noticed increased permeability of mannitol and decreased TEER value at higher concentration of ECG. As an explanation, the authors suggested the opening of TJ (Vaidyanathan \& Walle, 2003). In another example, loading of green tea extract to the basal side of transwell system led to a significant drop of TEER value, indicating the effect on the monolayer integrity (Zhang, Chow, \& Zuo, 2006). No effect was observed when the same concentration was loaded at the apical side and no cytotoxicity was noted. Damage of the integrity of monolayers may have occurred with greater loading concentration of EC and EGC, concurrently showing a drop in TEER values (Chan, Zhang, \& Zuo, 2007). Similarly, A-type procyanidins of cranberries has been found to cause a decrease in TEER values. The authors did not pursue the issue and excluded those monolayers from the experiment (Ou, Percival, Zou, Khoo, \& Gu, 2012). Shoij et al. (2006) reported that high molecular weight polymers from apples positively influenced the absorption of PC oligomers in rats, although they were not absorbed themselves. Similar effects of tetramers on absorption of procyanidin B2 by rats was observed by Appeldoorn, Vincken, Gruppen, \& Hollman (2009). Also Kosińska and Andlauer (2012) reported that incubation with cocoa procyanidins enhanced Caco-2 monolayer permeability, reflected in increased LY flux. Conversely, Erlejman, Fraga, and Oteiza (2006) observed a significant increase in TEER value as a result of incubation with hexameric fraction of procyanidins, which at the same time did not affect transcellular and paracellular transport in Caco-2 monolayers. Moreover, procyanidins protected Caco-2 monolayers from bile acids induced cytotoxicity and alterations in TJ protein (ZO-1) distribution and barrier integrity. Similarly, Déprez et al. showed increased TEER as an effect of addition of procyanidins (Déprez et al., 2001). Striking changes in the actin cytoskeleton of the polarised intestinal epithelial cell line Caco-2 upon cranberry treatment has been revealed but the mechanism of this phenomenon was not characterised (Harmidy, Tufenkji, \& Gruenheid, 2011).

\section{Concluding remarks}

The paracellular flux of molecules is very limited, and involves mainly hydrophilic molecules. A wide range of bioactive compounds, including a large percentage of phenolic compounds, might be classified as hydrophilic, and their low intestinal absorption has been demonstrated (Déprez et al., 2001; Scalbert et al., 2000; Shoji et al., 2006). Small changes in the tightness of paracellular spaces can significantly affect the permeability of paracellularly permeating molecules (Laitinen et al., 2004). The idea of influencing TJ integrity to increase the absorption of beneficial compounds is intriguing. Opening of TJs must be safe; for this reason, food extracts and food components are of high interest. Simultaneously, TJ opening has to be reversible and occur at a suitable time to diminish the risk that the opening of TJs for a molecule of interest results in the enhanced transport of undesirable molecules, toxins or pathogens across protective barriers of the gastrointestinal tract. The need of adequate cell models to study TJ modulations is acute and undeniable.

It appears that efforts to transiently weaken the paracellular barrier in order to enable the passage of macromolecules could aim to affect the leak pathway rather than the pore pathway. As discussed in the preceeding sections, the leak pathway is associated with ZO-1 and actomyosin changes. Two main possible mechanisms of action could be suggested: direct targeting of TJ proteins or signalling pathways regulating TJ function. The final effect of modulation of these signalling pathways is the phosphorylation of TJ proteins or the contraction/ relaxation of the PAMR. Nevertheless, the mechanism of TJ opening due to the action of food components is still to be explored in order to enable its target application of increasing absorption of beneficial compounds. This aspect is worth considering in the design of functional food, since the idea of TJ modulation as an approach to modify intestinal absorption of bioactive compounds is extremely promising.

\section{Acknowledgements}

AK was supported by the Scientific Exchange Programme founded by Rectors' Conference of the Swiss Universities (CRUS, Project code: 10.127). We would like to express our gratitude to Dr. Magdalena Karamać for drawing figures, to Dr. Bruno Schnyder for discussion 
on the manuscript and to Dr. Miriam Goyder for proofreading of the manuscript.

\section{References}

Aaby, K., Ekeberg, D., \& Skrede, G. (2007). Characterization of phenolic compounds in strawberry (Fragaria $\times$ ananassa) fruits by different HPLC detectors and contribution of individual compounds to total antioxidant capacity. Journal of Agricultural and Food Chemistry, 55, 4395-4406.

Al Sadi, R. M., \& Ma, T. Y. (2007). IL-1 beta causes an increase in intestinal epithelial tight junction permeability. The Journal of Immunology, 178, 4641-4649.

Al-Sadi, R., Khatib, K., Guo, S. H., Ye, D. M., Youssef, M., \& Ma, T. (2011). Occludin regulates macromolecule flux across the intestinal epithelial tight junction barrier American Journal of Physiology - Gastrointestinal and Liver Physiology, 300, G1054G1064.

Amasheh, M., Schlichter, S., Amasheh, S., Mankertz, J., Zeitz, M., Fromm, M., et al. (2008). Quercetin enhances epithelial barrier function and increases claudin-4 expression in Caco-2 cells. The Journal of Nutrition, 138, 1067-1073.

Anderson, J. M., \& Van Itallie, C. M. (2009). Physiology and function of the tight junction. Cold Spring Harbor Perspectives in Biology, 1, 1-16.

Appeldoorn, M. M., Vincken, J. P., Gruppen, H., \& Hollman, P. C. H. (2009). Procyanidin dimers A1, A2, and B2 are absorbed without conjugation or methylation from the small intestine of rats. The Journal of Nutrition, 139, 1469-1473.

Assimakopoulos, S. F., Papageorgiou, I., \& Charonis, A. (2011). Enterocytes' tight junctions: From molecules to diseases. World Journal of Gastrointestinal Pathophysiology, 2, 123-137.

Balda, M. S., \& Matter, K. (2008). Tight junctions at a glance. Journal of Cell Science, 121, 3677-3682.

Ballard, S. T., Hunter, J. H., \& Taylor, A. E. (1995). Regulation of tight-junction permeability during nutrient absorption across the intestinal epithelium. Annual Review of Nutrition, 15, 35-55.

Bergmann, H., Rogoll, D., Scheppach, W., Melcher, R., \& Richling, E. (2009). The Ussing type chamber model to study the intestinal transport and modulation of specific tight-junction genes using a colonic cell line. Molecular Nutrition \& Food Research, 53, 1211-1225.

Blomhoff, R., Carlsen, M. H., Andersen, L. F., \& Jacobs, D. R. (2006). Health benefits of nuts: Potential role of antioxidants. The British Journal of Nutrition, 96, S52-S60.

Borchardt, R. (2011). Hidalgo, I. J., Raub, T. J., and Borchardt, R. T.: Characterization of the human colon carcinoma cell line (Caco-2) as a model system for intestinal epithelial permeability, Gastroenterology, 96, 736-749, 1989, The backstory. The AAPS Journal, 13, 323-327.

Boyer, J., \& Liu, R. (2004). Apple phytochemicals and their health benefits. Nutrition Journal, 3, 5.

Chan, K. Y., Zhang, L., \& Zuo, Z. (2007). Intestinal efflux transport kinetics of green te catechins in Caco-2 monolayer model. The Journal of Pharmacy and Pharmacology, 59, 395-400.

Chen, W. Y., Lu, Z. L., Viljoen, A., \& Hamman, J. (2009). Intestinal drug transport enhancement by Aloe vera. Planta Medica, 75, 587-595.

Cho, S., Kim, J., Li, H., Shim, C., Linhardt, R., \& Kim, Y. (2002). Enhancement of paracellular transport of heparin disaccharide across Caco-2 cell monolayers. Archives of Pharmacal Research, 25, 86-92.

Christensen, J., El Gebali, S., Natoli, M., Sengstag, T., Delorenzi, M., Bentz, S., et al. (2012). Defining new criteria for selection of cell-based intestinal models using publicly available databases. BMC Genomics, 13, 274.

Colegio, O. R., Van Itallie, C. M., Mccrea, H. J., Rahner, C., \& Anderson, J. M. (2002). Claudins create charge-selective channels in the paracellular pathway between epithelial cells. American Journal of Physiology. Cell Physiology, 283, C142-C147.

Deli, M. A. (2009). Potential use of tight junction modulators to reversibly open membranous barriers and improve drug delivery. Biochimica et Biophysica Acta (BBA)Biomembranes, 1788, 892-910.

Déprez, S., Mila, I., Huneau, J. F., Tome, D., \& Scalbert, A. (2001). Transport of proanthocyanidin dimer, trimer, and polymer across monolayers of human intestinal epithelial Caco-2 cells. Antioxidants E Redox Signaling, 3, 957-967.

Eguchi, A., Murakami, A., \& Ohigashi, H. (2005). Novel bioassay system for evaluating anti-oxidative activities of food items: Use of basolateral media from differentiated Caco-2 cells. Free Radical Research, 39, 1367-1375.

Epriliati, I., D'Arcy, B., \& Gidley, M. (2009). Nutriomic analysis of fresh and processed fruit products. 2. During in vitro simultaneous molecular passages using Caco-2 cell monolayers. Journal of Agricultural and Food Chemistry, 57, 3377-3388.

Erlejman, A. G., Fraga, C. G., \& Oteiza, P. I. (2006). Procyanidins protect Caco-2 cells from bile acid- and oxidant-induced damage. Free Radical Biology \& Medicine, 41 $1247-1256$

Farquhar, M. G., \& Palade, G. E. (1963). Junctional complexes in various epithelia. The Journal of Cell Biology, 17, 375-412.

Fihn, B. M., Sjoqvist, A., \& Jodal, M. (2000). Permeability of the rat small intestinal epithelium along the villus-crypt axis: Effects of glucose transport. Gastroenterology, 119, 1029-1036.

Fogh, J., Fogh, J. M., \& Orfeo, T. (1977). 127 cultured human tumor-cell lines producing tumors in nude mice. Journal of the National Cancer Institute, 59, 221-226.

Förster, C. (2008). Tight junctions and the modulation of barrier function in disease. Histochemistry and Cell Biology, 130, 55-70.

Fuller, E., Duckham, C., \& Wood, E. (2007). Disruption of epithelial tight junctions by yeast enhances the paracellular delivery of a model protein. Pharmaceutical Research, 24, 37-47.
Furuse, M. (2010). Molecular basis of the core structure of tight junctions. Cold Spring Harbor Perspectives in Biology, 2, 1-14.

Gonzalez, R., Ballester, I., Lopez-Posadas, R., Suarez, M., Zarzuelo, A., Martinez-Augustin, O., et al. (2011). Effects of flavonoids and other polyphenols on inflammation. Critical Reviews in Food Science and Nutrition, 51, 331-362.

González-Mariscal, L., Tapia, R., \& Chamorro, D. (2008). Crosstalk of tight junction components with signaling pathways. Biochimica et Biophysica Acta (BBA)-Biomembranes, $1778,729-756$.

Gropper, S. S., Smith, J. J., \& Groff, J. L. (2009). Advanced Nutrition and Human Metabolism (5th edition). Australia; United States: Wadsworth/Cengage Learning.

Groschwitz, K. R., \& Hogan, S. P. (2009). Intestinal barrier function: Molecular regulation and disease pathogenesis. The Journal of Allergy and Clinical Immunology, 124, $3-20$.

Grube, S., Wolfrurn, U., \& Langguth, P. (2008). Characterization of the epithelial permeation enhancing effect of basic butylated methacrylate copolymer-In vitro studies. Biomacromolecules, 9, 1398-1405.

Hamazaki, Y., Itoh, M., Sasaki, H., Furuse, M., \& Tsukita, S. (2002). Multi-PDZ domain protein 1 (MUPP1) is concentrated at tight junctions through its possible interaction with claudin-1 and junctional adhesion molecule. The Journal of Biological Chemistry, 277, 455-461.

Harmidy, K., Tufenkji, N., \& Gruenheid, S. (2011). Perturbation of host cell cytoskeleton by cranberry proanthocyanidins and their effect on enteric infections. PLoS One, 6, $1-9$.

Hartsock, A., \& Nelson, W. J. (2008). Adherens and tight junctions: Structure, function and connections to the actin cytoskeleton. Biochimica et Biophysica Acta (BBA)Biomembranes, 1778, 660-669.

Hashimoto, K., Matsunaga, N., \& Shimizu, M. (1994). Effect of vegetable extracts on the transepithelial permeability of the human intestinal Caco-2 cell monolayer. Bioscience, Biotechnology, and Biochemistry, 58, 1345-1346.

Hilgendorf, C., Spahn-Langguth, H., Regårdh, C. G., Lipka, E., Amidon, G. L., \& Langguth, P. (2000). Caco-2 versus Caco-2/HT29-MTX co-cultured cell lines: Permeabilities via diffusion, inside- and outside-directed carrier-mediated transport. Journal of Pharmaceutical Sciences, 89, 63-75.

Hilgers, A. R., Conradi, R. A., \& Burton, P. S. (1990). Caco-2 cell monolayers as a model for drug transport across the intestinal mucosa. Pharmaceutical Research, 7, 902-910.

Isoda, H., Han, J. Y., Tominaga, M., \& Maekawa, T. (2001). Effects of capsaicin on human intestinal cell line Caco-2. Cytotechnology, 36, 155-161.

Juuti-Uusitalo, K., Klunder, L. J., Sjollema, K. A., Mackovicova, K., Ohgaki, R., Hoekstra, D., et al. (2011). Differential effects of TNF (TNFSF2) and IFN-gamma on intestinal epithelial cell morphogenesis and barrier function in three-dimensional culture. PLoS One, 6.

Kang, M. J., Cho, J. Y., Shim, B. H., Kim, D. K., \& Lee, J. (2009). Bioavailability enhancing activities of natural compounds from medicinal plants. Journal of Medicinal Plants Research, 3, 1204-1211.

Konishi, Y. (2003). Modulations of food-derived substances on intestinal permeability in Caco-2 cell monolayers. Bioscience, Biotechnology, and Biochemistry, 67, 2297-2299.

Kosińska, A., \& Andlauer, W. (2012). Cocoa polyphenols are absorbed in Caco-2 cell model of intestinal epithelium. Food Chemistry, 135, 999-1005.

Kosińska, A., Karamać, M., Estrella, I., Hernandez, T., Bartolome, B., \& Dykes, G. A. (2012). Phenolic compound profiles and antioxidant capacity of Persea americana Mill. peels and seeds of two varieties. Journal of Agricultural and Food Chemistry, $60,4613-4619$

Kumar, N. M., \& Gilula, N. B. (1996). The gap junction communication channel. Cell, 84, $381-388$

Laitinen, L. A., Tammela, P. S. M., Galkin, A., Vuorela, H. J., Marvola, M. L. A., \& Vuorela, P. M. (2004). Effects of extracts of commonly consumed food supplements and food fractions on the permeability of drugs across Caco-2 cell monolayers. Pharmaceutical Research, 21, 1904-1916

Lal-Nag, M., \& Morin, P. (2009). The claudins. Genome Biology, 10, 235.

Langerholc, T., Maragkoudakis, P. A., Wollgast, J., Gradisnik, L., \& Cencic, A. (2011). Novel and established intestinal cell line models-An indispensable tool in food science and nutrition. Trends in Food Science E Technology, 22, S11-S20.

Lebitsa, T., Viljoen, A., Lu, Z. L., \& Hamman, J. (2012). In vitro drug permeation enhancement potential of aloe gel materials. Current Drug Delivery, 9, 297-304.

Li, N., Lewis, P., Samuelson, D., Liboni, K., \& Neu, J. (2004). Glutamine regulates Caco-2 cell tight junction proteins. American Journal of Physiology - Gastrointestinal and Liver Physiology, 287, G726-G733.

Linnankoski, J., Mäkelä, J., Palmgren, J., Mauriala, T., Vedin, C., Ungell, A. L., et al. (2010). Paracellular porosity and pore size of the human intestinal epithelium in tissue and cell culture models. Journal of Pharmaceutical Sciences, 99, 2166-2175.

Lowe, P. J., Miyai, K., Steinbach, J. H., \& Hardison, W. G. M. (1988). Hormonal regulation of hepatocyte tight junctional permeability. The American Journal of Physiology, 255, G454-G461.

Lu, Z. L., Chen, W. Y., Viljoen, A., \& Hamman, J. H. (2010). Effect of sinomenine on the in vitro intestinal epithelial transport of selected compounds. Phytotherapy Research, 24, 211-218.

Madara, J. L. (2011). Functional morphology of epithelium of the small intestine. Comprehensive Physiology, 83-120.

Mariano, C., Sasaki, H., Brites, D., \& Brito, M. A. (2011). A look at tricellulin and its role in tight junction formation and maintenance. European Journal of Cell Biology, 90, 787-796.

Martín-Padura, I., Lostaglio, S., Schneemann, M., Williams, L., Romano, M., Fruscella, P., et al. (1998). Junctional adhesion molecule, a novel member of the immunoglobulin superfamily that distributes at intercellular junctions and modulates monocyte transmigration. The Journal of Cell Biology, 142, 117-127. 
Noda, S., Tanabe, S., \& Suzuki, T. (2012). Differential effects of flavonoids on barrier integrity in human intestinal Caco-2 cells. Journal of Agricultural and Food Chemistry, $60,4628-4633$.

Ohno, Y., Naganuma, T., Ogawa, T., \& Muramoto, K. (2006). Effect of lectins on the transport of food factors in Caco-2 cell monolayers. Journal of Agricultural and Food Chemistry, 54, 548-553.

Ou, K., Percival, S. S., Zou, T., Khoo, C., \& Gu, L. (2012). Transport of cranberry A-type procyanidin dimers, trimers, and tetramers across monolayers of human intestinal epithelial Caco-2 cells. Journal of Agricultural and Food Chemistry, 60, 1390-1396.

Pinto, M., Robineleon, S., Appay, M. D., Kedinger, M., Triadou, N., Dussaulx, E., et al. (1983). Enterocyte-like differentiation and polarization of the human-colon carcinoma cell-line Caco-2 in culture. Biology of the Cell, 47, 323-330.

Raleigh, D. R., Boe, D. M., Yu, D., Weber, C. R., Marchiando, A. M., Bradford, E. M., et al. (2011). Occludin S408 phosphorylation regulates tight junction protein interactions and barrier function. The Journal of Cell Biology, 193, 565-582.

Rapin, J. R., \& Wiernsperger, N. (2010). Possible links between intestinal permeability and food processing: A potential therapeutic niche for glutamine. Clinics, 65, 635-643.

Rodgers, L. S., \& Fanning, A. S. (2011). Regulation of epithelial permeability by the actin cytoskeleton. Cytoskeleton, 68, 653-660.

Runswick, S. K., O'Hare, M. J., Jones, L., Streuli, C. H., \& Garrod, D. R. (2001). Desmosomal adhesion regulates epithelial morphogenesis and cell positioning. Nature Cell Biology, 3, 823-830.

Sadowski, D. C., \& Meddings, J. B. (1993). Luminal nutrients alter tight-junction permeability in the rat jejunum-An in-vivo perfusion model. Canadian Journal of Physiology and Pharmacology, 71, 835-839.

Salama, N. N., Eddington, N. D., \& Fasano, A. (2006). Tight junction modulation and its relationship to drug delivery. Advanced Drug Delivery Reviews, 58, 15-28.

Sambuy, Y., De Angelis, I., Ranaldi, G., Scarino, M. L., Stammati, A., \& Zucco, F. (2005). The Caco-2 cell line as a model of the intestinal barrier: Influence of cell and culture-related factors on Caco-2 cell functional characteristics. Cell Biology and Toxicology, 21, 1-26.

Scalbert, A., Deprez, S., Mila, I., Albrecht, A. M., Huneau, J. F., \& Rabot, S. (2000). Proanthocyanidins and human health: Systemic effects and local effects in the gut. Biofactors, 13, 115-120.

Schonhoff, S. E., Giel-Moloney, M., \& Leiter, A. B. (2004). Minireview: Development and differentiation of gut endocrine cells. Endocrinology, 145, 2639-2644.

Schulzke, J. D., Gunzel, D., John, L. J., \& Fromm, M. (2012). Perspectives on tight junction research. Annals of the New York Academy of Sciences, 1257, 1-19.

Seeram, N. P. (2008). Berry fruits for cancer prevention: Current status and future prospects. Journal of Agricultural and Food Chemistry, 56, 630-635.

Seeram, N. P., Adams, L. S., Zhang, Y., Lee, R., Sand, D., Scheuller, H. S., et al. (2006). Blackberry, black raspberry, blueberry, cranberry, red raspberry, and strawberry extracts inhibit growth and stimulate apoptosis of human cancer cells in vitro. Journal of Agricultural and Food Chemistry, 54, 9329-9339.

Sharma, M., Li, L. Y., Celver, J., Killian, C., Kovoor, A., \& Seeram, N. P. (2010). Effects of fruit ellagitannin extracts, ellagic acid, and their colonic metabolite, urolithin A on Wnt signaling. Journal of Agricultural and Food Chemistry, 58, 3965-3969.

Shen, L., Weber, C. R., Raleigh, D. R., Yu, D., \& Tumer, J. R. (2011). Tight junction pore and leak pathways: A dynamic duo. Annual Reviews of Physiology, 73, 283-309.

Shimizu, M. (1999). Modulation of intestinal functions by food substances. Nahrung-Food, 43, 154-158.

Shoji, T., Masumoto, S., Moriichi, N., Akiyama, H., Kanda, T., Ohtake, Y., et al. (2006). Apple procyanidin oligomers absorption in rats after oral administration: Analysis of procyanidins in plasma using the porter method and high-performance liquid chromatography/tandem mass spectrometry. Journal of Agricultural and Food Chemistry, 54, 884-892.

Soderholm, J. D., Oman, H., Blomquist, L., Veen, J., Lindmark, T., \& Olaison, G. (1998). Reversible increase in tight junction permeability to macromolecules in rat ileal mucosa in vitro by sodium caprate, a constituent of milk fat. Digestive Diseases and Sciences, 43, 1547-1552.

Son, T. G., Camandola, S., \& Mattson, M. P. (2008). Hormetic dietary phytochemicals. Neuromolecular Medicine, 10, 236-246.

Steed, E., Balda, M. S., \& Matter, K. (2010). Dynamics and functions of tight junctions. Trends in Cell Biology, 20, 142-149.

Sun, H., Chow, E. C., Liu, S., Du, Y., \& Pang, K. S. (2008). The Caco-2 cell monolayer: Usefulness and limitations. Expert Opinion on Drug Metabolism \& Toxicology, 4, 395-411.

Suzuki, T., \& Hara, H. (2004). Various nondigestible saccharides open a paracellular calcium transport pathway with the induction of intracellular calcium signalling in human intestinal Caco-2 cells. The Journal of Nutrition, 134, 1935-1941.
Suzuki, T., Nishimukai, M., Takechi, M., Taguchi, H., Hamada, S., Yokota, A., et al. (2010) The nondigestible disaccharide epilactose increases paracellular Ca sbsorption via Rho-associated kinase- and myosin light chain kinase-dependent mechanisms in rat small intestines. Journal of Agricultural and Food Chemistry, 58, 1927-1932.

Suzuki, T., \& Hara, H. (2009). Quercetin enhances intestinal barrier function through the assembly of zonnula occludens-2, occludin, and claudin- 1 and the expression of claudin-4 in Caco-2 cells. The Journal of Nutrition, 139, 965-974.

Suzuki, T., Tanabe, S., \& Hara, H. (2011). Kaempferol enhances intestinal barrier function through the cytoskeletal association and expression of tight junction proteins in Caco-2 cells. The Journal of Nutrition, 141, 87-94.

Terry, S., Nie, M., Matter, K., \& Balda, M. S. (2010). Rho signaling and tight junction functions. Physiology, 25, 16-26.

Tsukamoto, T., \& Nigam, S. K. (1999). Role of tyrosine phosphorylation in the reassembly of occludin and other tight junction proteins. American Journal of Physiology. Renal Physiology, 276, F737-F750.

Tsukura, Y., Mori, M., Hirotani, Y., Ikeda, K., Amano, F., Kato, R., et al. (2007). Effects of capsaicin on cellular damage and monolayer permeability in human intestinal Caco-2 cells. Biological \& Pharmaceutical Bulletin, 30, 1982-1986.

Turner, J. R. (2000). Show me the pathway! Regulation of paracellular permeability by $\mathrm{Na}(+)$-glucose cotransport. Advanced Drug Delivery Reviews, 41, 265-281.

Ulluwishewa, D., Anderson, R. C., McNabb, W. C., Moughan, P. J., Wells, J. M., \& Roy, N. C. (2011). Regulation of tight junction permeability by intestinal bacteria and dietary components. The Journal of Nutrition, 141, 769-776.

Vaidyanathan, J. B., \& Walle, T. (2003). Cellular uptake and efflux of the tea flavonoid (-)-epicatechin-3-gallate in the human intestinal cell line Caco-2. The Journal of Pharmacology and Experimental Therapeutics, 307, 745-752.

Van Itallie, C. M., \& Anderson, J. M. (2006). Claudins and epithelial paracellular transport. Annual Reviews of Physiology, 68, 403-429.

Van Itallie, C. M., Fanning, A. S., Bridges, A., \& Anderson, J. M. (2009). ZO-1 stabilizes the tight junction solute barrier through coupling to the perijunctional cytoskeleton. Molecular Biology of the Cell, 20, 3930-3940.

Van Itallie, C. M., Holmes, J., Bridges, A., Gookin, J. L., Coccaro, M. R., Proctor, W., et al. (2008). The density of small tight junction pores varies among cell types and is increased by expression of claudin-2. Journal of Cell Science, 121, 298-305.

Van Itallie, C. M., Fanning, A. S., Holmes, J., \& Anderson, J. M. (2010). Occludin is required for cytokine-induced regulation of tight junction barriers. Journal of Cell Science, 123, 2844-2852.

Vreeburg, R. A. M., Bastiaan-Net, S., \& Mes, J. J. (2011). Normalization genes for quantitative RT-PCR in differentiated Caco-2 cells used for food exposure studies. Food $\mathcal{E}$ Function, 2, 124-129.

Vreeburg, R. A., van Wezel, E. E., Ocana-Calahorro, F., \& Mes, J. J. (2012). Apple extract induces increased epithelial resistance and claudin 4 expression in Caco-2 cells. Journal of the Science of Food and Agriculture, 92, 439-444.

Ward, P. D., Tippin, T. K., \& Thakker, D. R. (2000). Enhancing paracellular permeability by modulating epithelial tight junctions. Pharmaceutical Science \& Technology Today, 3, 346-358.

Weinreb, O., Amit, T., Mandel, S., \& Youdim, M. B. H. (2009). Neuroprotective molecular mechanisms of (-)-epigallocatechin-3-gallate: A reflective outcome of its antioxidant, iron chelating and neuritogenic properties. Genes and Nutrition, 4, 283-296.

Wu, C., Xu, H., Héritier, J., \& Andlauer, W. (2012). Determination of catechins and flavonol glycosides in Chinese tea varieties. Food Chemistry, 132, 144-149.

Xie, Y., Kosińska, A., Xu, H., \& Andlauer, W. (2012). Milk enhances intestinal absorption of green tea catechins in in vitro digestion/Caco-2 cells model. Food Research International, http://dx.doi.org/10.1016/j.foodres.2012.07.063.

Xu, J. G., Go, M. L., \& Lim, L. Y. (2003). Modulation of digoxin transport across Caco-2 cell monolayers by citrus fruit juices: Lime, lemon, grapefruit, and pummelo. Pharmaceutical Research, 20, 169-176.

Yamazaki, Y., Tokumasu, R., Kimura, H., \& Tsukita, S. (2011). Role of claudin species-specific dynamics in reconstitution and remodeling of the zonula occludens. Molecular Biology of the Cell, 22, 1495-1504.

Yasumatsu, H., \& Tanabe, S. (2010). The casein peptide Asn-Pro-Trp-Asp-Gln enforces the intestinal tight junction partly by increasing occludin expression in Caco-2 cells. The British Journal of Nutrition, 104, 951-956.

Yu, A. S. L. (2009). Molecular basis for cation selectivity in claudin-2-based pores. Annals of the New York Academy of Sciences, 1165, 53-57.

Zhang, L., Chow, M. S. S., \& Zuo, Z. (2006). Effect of the co-occurring components from green tea on the intestinal absorption and disposition of green tea polyphenols in Caco-2 monolayer model. The Journal of Pharmacy and Pharmacology, 58, 37-44.

Zweibaum, A., Laburthe, M., Grasset, E., \& Louvard, D. (2011). Use of cultured cell lines in studies of intestinal cell differentiation and function. Comprehensive Physiology 223-255. 